C6if- $9.207 .266--5$

THE RERTR PROGRAM: A STATUS REPORT*

ANL/EP/CP-77799

DE93 002926

\author{
A. Travelli
}

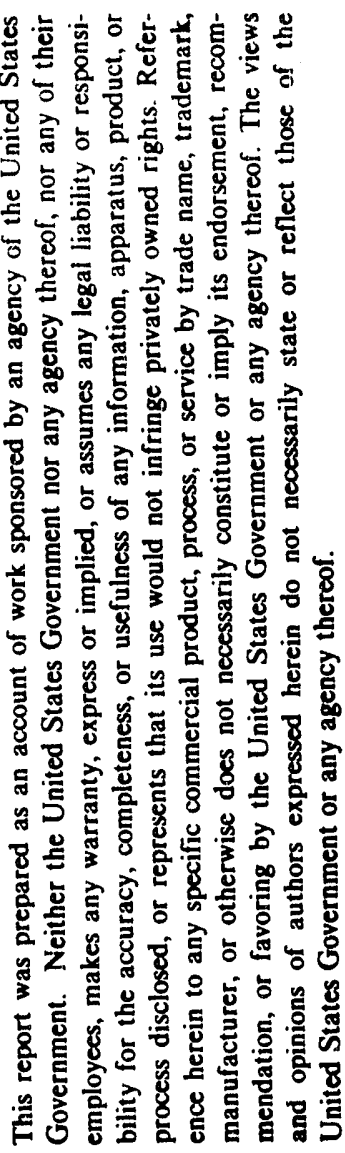

Argonne National Laboratory

Argonne, Illinois 60439 USA

To be Presented at the

1992 International Meeting on

Reduced Enrichment for

Research and Test Reactors

September 27 - Jctober 11992

Roskilde, Denmark

The submitted manuscript has been authored
by a contractor of the U.S. Government
under contract No. W.31-109ENG.38.
Accordingly, the U. S. Government retains a
nonexclusive, royalty-free license to publish
or reproduce the published form of this
contribution, or allow others to do so, for
U. S. Government purposes.

*Work supported by the U.S. Department of Energy, Office of Arms Control and Nonproliferation under Contract No. W-31-109-ENG-38. 


\title{
THE RERTR PROGRAM: A STATUS REPORT
}

\author{
A. Travelli \\ Argonne National Laboratory \\ Argonne, Illinois, USA
}

\begin{abstract}
The progress of the Reduced Enrichment Research and Test Reactor (RERTR) Program is described. The major events, findings, and activities of 1991 are reviewed after a brief summary of the results which the RERTR Program had achieved by the end of 1991 in collaboration with its many international partners.
\end{abstract}

The disappearance of the Soviet Union, the cooperative attitude of the republics which have taken its place, and the end of the Cold War have affected the RERTR program in several ways. The program is now managed by the DOE Office of Arms Control and Nonproliferation, which directs all arms control and nonproliferation activities within DOE, and is part of the ANL Arms Control and Nonproliferation Program, which directs all corresponding activities at Argonne National Laboratory.

The program would welcome the opportunity of cooperating with the CIS republics towards the elimination of Russian-origin HEU from international commerce. With renewed interest in nonproliferation, Congress came very close to funding resumption of RERTR fuel development and promised to reconsider the issue.

The technical efforts of the RERTR Program were concentrated on technology transfer and implementation activities, c snsistent with DOE guidance. Existing fuel data were analyzed and interpr 3 ted to derive a better understanding of the behavior of dispersion fuels under irradiation. Computer codes were modified and upgraded for the analysis of research reactors operating with LEU fuels. In particular, the WIMS-D4 code was benchmarked by comparison with a Monte Carlo code. Analyses, calculations, and safety evaluations were conducted to support LEU conversions of both US and foreign research reactors.

One more U.S. university reactor has been converted to LEU fuel, bringing the total to six converted U.S. reactors. An approximate quantitative evaluation of the overall LEU conversion progress shows that about $56 \%$ of the work required to eliminate the need for further $\mathrm{HEU}$ exports has been accomplished.

The major current program goal is to work closely with the various reactor and fuel fabrication organizations that are pursuing LEU conversions, so that their objective can be attained at the earliest possible date. International cooperation continues to be essential to the achievement of this goal. 


\section{INTRODUCTION}

Very few years, in the history of mankind, will be remembered as having brought more change to the way we live and interact with the rest of the world than the past twelve months. The Soviet Union has disappeared, fifteen new republics have emerged in its place, and these republics have repudiated communism and established friendly and cooperative relations with the West: in short, the Cold War is over. The single, powerful, dangerous adversary which the West has opposed at great cost for nearly half a century no longer exists. In its place, the major current threat to international stability comes from many smaller countries where nationalistic, ethnic, or religious motives may encourage the development and use of weapons of mass destruction.

Much of the attention and resources that used to be dedicated to waging the Cold War are now turning to nonproliferation. Elimination of the international traffic in weapons-grade materials is viewed as an essential step in hindering proliferation of nuclear weapons, and the Reduced Enrichment Research and Test Reactor (RERTR) Program and the international organizations associated with it find themselves squarely in the focus of this effort.

The RERTR Program was established in 1978 by the Department of Energy (DOE), which continues to fund and manage the program in coordination with the Arms Control and Disarmament Agency (ACDA), the Department of State (DOS), and the Nuclear Regulatory Commission (NRC). The primary objective of the program is to develop the technology needed to use Low-Enrichment Uranium (LEU) instead of High-Enrichment Uranium (HEU) in the research and test reactors whose fuel requirements cause most of the HEU traffic, and to do so without significant penalties in experiment performance, economics, or safety aspects of the reactors.

Close cooperation with the many international organizations represented at this meeting has been the cornerstone of the RERTR Program since its beginning and since its first international meeting fourteen years ago. This cooperation and the high quality of the technical contributions which many partners have brought to the overall effort are to be credited for much of the progress which the program has achieved to date.

Cooperation between the RERTR Program and RIS $\varnothing$ began in 1980, when the International Atomic Energy Agency assembled a team of experts to assess the feasibility of converting heavy-water moderated research reactors to the use of LEU fuels. Dr. Haack was there to represent the DR-3 reactor. That was the beginning of a long and fruitful interaction centering on the performance, safety, and fabrication of the new silicide fuels that Argonne was developing. Two RIS $\emptyset$ scientists visited ANL in 1984 to learn about the fabrication process, and ANL personnel returned the visit in 1985. It was a resounding success for all of us when, at the 1990 meeting in Newport, Dr. Haack announced that the DR-3 had become the first European research reactor to convert to LEU silicide fuel, and that it had done so with indigenously fabricated fuel.

It gives me a special pleasure to take part in this International RERTR Meeting in Denmark, in close proximity to the RISØ National Laboratory and its DR-3 reactor. As you know, a long-standing tradition of the RERTR meetings is that even-year meetings are held in the United States, but the accomplishments that our RIS $\emptyset$ colleagues had to report were 
so exceptional that the U.S. RERTR Program decided to yield the site of this meeting to RISØ. From the interest that this meeting has aroused, as evidenced by the preliminary list of attendees, we know that our decision was right. We look forward to an excellent program, to interesting technical exchanges, to touring the converted DR-3 reactor and the fuel fabrication facilities, to visiting with old friends, and to the traditional hospitality of this beautiful country.

\section{OVERVIEW OF THE SEPTEMBER 1991 PROGRAM STATUS}

By September 1991, when the last International RERTR Meeting was held ${ }^{[1]}$, the main results achieved in the fuel development area were:

(a) The qualified uranium densities of the three main fuels which were in operation with $\mathrm{HEU}$ in research reactors when the program began (UAl $-\mathrm{Al}$ with up to $1.7 \mathrm{~g} \mathrm{U} / \mathrm{cm}^{3}$;

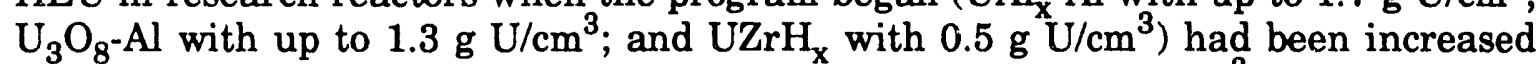
significantly. The new uranium densities extended up to $2.3 \mathrm{~g} \mathrm{U} / \mathrm{cm}^{3}$ for $\mathrm{UAl}_{\mathrm{x}}-\mathrm{Al}, 3.2$ $\mathrm{g} \mathrm{U} / \mathrm{cm}^{3}$ for $\mathrm{U}_{3} \mathrm{O}_{8}-\mathrm{Al}$, and $3.7 \mathrm{~g} \mathrm{U} / \mathrm{cm}^{3}$ for $\mathrm{UZrH}_{\mathrm{x}}$. Each fuel had been tested extensively up to these densities and, in some cases, beyond them. All the data needed to qualify these fuel types with LEU and with the higher uranium densities had been collected.

(b) For $\mathrm{U}_{3} \mathrm{Si}_{2}-\mathrm{Al}$, after reviewing the data collected by the program, the U.S. Nuclear Regulatory Commission (NRC) had issued a formal and generic approval ${ }^{[2]}$ of the use of $\mathrm{U}_{3} \mathrm{Si}_{2}-\mathrm{Al}$ fuel in research and test reactors, with uranium densities up to $4.8 \mathrm{~g} / \mathrm{cm}^{3}$. A whole-core demonstration using this fuel had been successfully completed in the ORR using a mixed-core approach.

(c) For $\mathrm{U}_{3} \mathrm{Si}-\mathrm{Al}$, miniplates with up to $6.1 \mathrm{~g} \mathrm{U} / \mathrm{cm}^{3}$ had been fabricated by ANL and the CNEA, and irradiated to $84-96 \%$ in the Oak Ridge Research Reactor (ORR). PIE of these miniplates had given good results, but had shown that some burnup limits might need to be imposed for the higher densities. Four full-size plates fabricated by CERCA with up to $6.0 \mathrm{~g} \mathrm{U} / \mathrm{cm}^{3}$ had been successfully irradiated to $53-54 \%$ burnup in SILOE, and a full-size $\mathrm{U}_{3} \mathrm{Si}-\mathrm{Al}\left(6.0 \mathrm{~g} \mathrm{U} / \mathrm{cm}^{3}\right)$ element, also fabricated by CERCA, had been successfully irradiated in SILOE to $55 \%$ burnup. However, conclusive evidence indicating that $\mathrm{U}_{3} \mathrm{Si}$ became amorphous under irradiation had convinced the RERTR Program that this material as then developed could not be used safely beyond the limits established by the SILOE irradiations.

(d) Two concepts based on hot-isostatic pressing (HIP) procedures had been developed for LEU silicide fuels with the potential of holding effective uranium densities much greater than $4.8 \mathrm{~g} \mathrm{U} / \mathrm{cm}^{3}$. One of the concepts was based on a composite structure of $\mathrm{U}_{3} \mathrm{Si}$ wires and aluminum (up to $12.9 \mathrm{~g} \mathrm{U} / \mathrm{cm}^{3}$ ), while the other was based on a $\mathrm{U}_{3} \mathrm{Si}_{2}$-Al dispersion structure (up to $10.2 \mathrm{~g} \mathrm{U} / \mathrm{cm}^{3}$ ). Sample miniplates had been produced for both concepts.

In other important program areas, reprocessing studies at the Savannah River Laboratory had concluded that the RERTR fuels could be successfully reprocessed at the Savannah River Plant and DOE had defined the terms and conditions under which these fuels will be accepted for reprocessing. 
A new analytical/experimental program had begun to determine the feasibility of using LEU instead of HEU in fission targets dedicated to the production of ${ }^{99}$ Mo for medical applications. A procedure for basic dissolution and processing of LEU silicide targets had been developed and was ready for demonstration on a full-size target with prototypic burnup.

Extensive studies had been conducted, with favorable results, on the performance, safety, and economic characteristics of LEU conversions. These studies included many joint study programs, which were in progress for about 28 reactors from 17 different countries.

Coordination of the safety calculations and evaluations was continuing for the US university reactors planning to convert to LEU as required by the $1986 \mathrm{NRC}$ rule. Five of these reactors had already been converted, two other safety evaluations had been completed, and calculations for five more reactors were in progress.

DOE guidance received at the beginning of 1990 had redirected the efforts of the US RERTR Program away from the development of new and better fuels, toward the transfer of already developed fuel technologies, and toward providing assistance to reactors undergoing conversion.

\section{PROGRESS OF THE RERTR PROGRAM IN 1992}

The historical events which have occurred during the past twelve months and which were mentioned in the introduction have affected the RERTR Program in several ways.

At the beginning of 1992, shortly after the USSR flag was hauled down at the Kremlin, DOE announced a reorganization which concentrated all DOE activities related to arms control and nonproliferation within the Office of Arms Control and Nonproliferation (OAN), reporting directly to the Secretary of Energy. Since then, management of the RERTR program has been assumed by DOE/OAN, which appears to be particularly well suited to supporting and managing the program.

Shortly after DOE's action, Argonne National Laboratory also consolidated all its activities related to arms control and nonproliferation in a single office, the ANL Arms Control and Nonproliferation (ACNP) Program, of which the RERTR program became an important component. The net result is that the RERTR program now has access to enhanced resources and personnel.

Since its inception, the RERTR program has limited its efforts to eliminating the international traffic in HEU of U.S. or other Western origin. This qualifier was required not by any intrinsic safety of the HEU produced in the Soviet Union, but by our admitted inability to influence that country's policies. The end of the Cold War and the new friendly relations with the republics which have replaced the Soviet Union have made that qualifier unnecessary. We would welcome the establishment of a CIS RERTR program and stand ready to cooperate with it to the fullest extent. We would also encourage all our many international partners to join us in this effort, to eliminate the dangers of HEU traffic from those parts of the world which were closed to us while the Cold War was being waged. 
A plan to resume development of LEU fuels with uranium densities higher than the currently qualified $4.8 \mathrm{~g} / \mathrm{cm}^{3}$ was prepared by the RERTR program and submitted to DOE. Acting independently from this submittal, last summer the U.S. House of Representatives voted to allocate enough funds to the RERTR program to resume its fuel development effort. The allocation was rescinded in mid-September in conference with the Senate, but the final bill requested DOE to provide Congress with a detailed description of the progress of the RERTR program and of the costs involved in resuming development of new fuels. Such development, of course, would greatly facilitate collaboration with a CIS RERTR program.

With the disappearance of the USSR, the smaller number of nuclear weapons needed to defend the U.S. against a potential attack, and the large number of weapons that must be destroyed according to arms control treaties, operation of expensive production reactors and related reprocessing plants became unnecessary. In 1992, DOE announced that the reprocessing plants at Savannah River and at the Idaho National Engineering Laboratory would be permanently shut down in the near future. While logical and probably unavoidable, this decision had important repercussions for the sesearch reactors whose fuel was normally reprocessed at those plants. All the work that the RERTR program and Savannah River personnel had accomplished to ensure that RERTR fuels could be reprocessed within the normal envelope of the Savannah River flowsheets became suddenly useless. We have a keen interest in the reprocessing solutions that are being pursued by reactor operators and potential reprocessors other than DOE, and we intend to cooperate as much as possible to ensure that a viable solution for reprocessing LEU fuels is found.

Consistent with DOE guidance, during the past year the RERTR Program has focused on the conversion of research reactors using the low-enrichment fuels which the program had already developed, and has concentrated its efforts on technology transfer and analytical assistance related to such conversions.

The main technical accomplishments of the program during 1992 are listed below.

1. The results of postirradiation examinations of dispersion fuels were further studied to derive a better understanding of the irradiation behavior, safety characteristics, and applicability of these fuels. ${ }^{[3]}$. Whenever needed, the results were transmitted to the operators of reactors preparing for conversion, so that they could be taken into account in the required safety evaluations.

2. Several computer codes have been modified and upgraded to improve our capability to analyze the performance and safety characteristics of research reactors operating with LEU fuels. In particular, a modified version of the WIMS-D4 code has been prepared which provides improved data in formats that can interface with U. S. diffusion and burnup codes. Qualification of the code has included detailed comparisons with the VIM Monte Carlo code. ${ }^{[4]}$

3. Analyses, calculations, and safety evaluations were performed for reactors undergoing or considering conversions outside the US, within the joint study agreements which are in effect between the RERTR Program and several international research reactor organizations. Contribution of the RERTR Program of special significance in this area concern the SSR reactor in Romania ${ }^{[5,6]}$ and the GRR-1 reactor in Greece. ${ }^{[7]}$ 
4. Analyses, calculations, and safety evaluations were also conducted to support US research reactors in their efforts to convert to LEU fuels as required by the US Nuclear Regulatory Commission. Some results of this work, concerning the Georgia Tech Reactor, are included in one of the papers presented at this meeting ${ }^{[8]}$.

I reported last year ${ }^{[1]}$ on the overall progress toward conversion which had been achieved by the end of 1991 toward the conversion to LEU fuels of all the research reactors which required HEU exports when the program began, and which were still in operation without imminent plans of being shut down. It is of interest to revisit the situation of these reactors today, and to see how much new progress has been accomplished during the intervening year.

The research reactors of interest for this review are the forty-one ${ }^{*}$ research reactors with power of at least one megawatt which used to import HEU either from the United States or from other Western sources. Listed below are the accomplishments of which we have become aware since the previous report was prepared. I hope that additional progress will be reported at this meeting.

1. The SSR reactor (14 MW), at INR in Pitesti, Romania, began the conversion to LEU TRIGA fuel with $45 \mathrm{wt} \%$ uranium in February 1992. Four LEU elements were successfully used to bring the reactor to power, and fourteen more LEU elements are expected to enter into use beginning next year.

2. The R-2 reactor ( $50 \mathrm{MW}$ ), at Studsvik, Sweden, continued its successful conversion effort to LEU silicide fuel. This conversion is expected to be complete by the end of 1992.

3. The KUR reactor ( $5 \mathrm{MW}$ ), at Kyoto University in Kyoto, Japan, began irradiation of two prototype LEU silicide elements in February 1992.

The list of the fully-converted reactors, which includes nine reactors (OSIRIS, THOR, PRR-1, DR-3, RA-3, FRG-1, ASTRA, NRCRR, and PARR), has not changed since last year, but several reactors have made significant advances towards conversion.

To assess the overall conversion progress, six important steps which most reactors are expected to take on their way toward conversion have been defined as detailed in Ref. 1:

1. Determine feasibility of conversion.

2. Develop conversion plan.

3. Begin irradiation of prototype elements.

4. Order LEU elements for conversion.

5. Load first LEU elements in the core.

6. Unload last HEU elements from the core. 
The forty-one operating reactors which required HEU exports when the RERTR Program began can be subdivided in seven categories according to the most advanced step which they have achieved. The two graphs of Fig. 1 illustrate the distributions of the numbers of the reactors, and of the average number of kilograms of ${ }^{235} U$ yearly exported for use in their fuels, among the various categories. Both diagrams would be blank if no progress toward reduction of HEU exports had been achieved, and fully shadowed if total success had been achieved and no further HEU exports were to be required. The percentages of accomplished work are now $55.7 \%$ for the number of reactors and $55.4 \%$ for the yearly ${ }^{235} \mathrm{U}$ exports, while they were both $54.9 \%$ last year. ${ }^{*}$ The incremental conversion progress recorded during the past year was not as remarkable as that recorded in 1981, but still points to an excellent overall conversion accomplishment. It must be recalled in this connection that, unless RERTR fuel development is resumed, four of the reactors considered in the diagrams cannot be converted: therefore, the highest fractions which are theoretically achievable are $90.2 \%$ and $79.1 \%$.

Comparable progress has been attained also by the U.S. university reactors, which are considered separately because they do not require HEU exports. The University of Missouri at Rolla Reactor was successfully converted to LEU silicide fuel, bringing the total number of U.S. converted reactors to six. Safety documentation was completed for one reactor and is nearly complete for five others. In addition, work was initiated for four TRIGA reactors using HEU fuel. The LEU conversion progress of the U. S. research reactors licensed by the U. S. Nuclear Regulatory Commission is discussed in Ref. 9.

\section{PLANNED ACTIVITIES}

The future activities which the RERTR Program plans to undertake are consistent with the recent DOE guidance and with the plan outlined at last year's international meeting. The major elements of this plan are described below.

1. Complete testing, analysis, and documentation of the fuels which have already been developed, and support their implementation.

2. Transfer LEU fuel fabrication technology to countries and organizations which require such assistance.

3. Perform calculations and evaluations for reactors planning to undergo conversion, to assist in improving performance and in resolving safety issues.

4. Within the available budget, develop a viable process, based on LEU, for the production of fission ${ }^{99} \mathrm{Mo}$ in research reactors.

*This value cited last year were slightly different, $54.4 \%$ and $54.8 \%$ because of the different base. 


\section{SUMMARY AND CONCLUSION}

The disappearance of the Soviet Union and the end of the Cold War have brought significant changes for the RERTR program. The new DOE Office of Arms Control and Nonproliferation is now responsible for all DOE arms control and nonproliferation activities, and has assumed management of the RERTR program. Similarly, the RERTR program is now an important component of the ANL Arms Control and Nonproliferation program. The program would welcome the opportunity to cooperate with the CIS republics towards the elimination of the international traffic in Russian-supplied HEU.

The new emphasis on nonproliferation has caused renewed interest in the program's accomplishments and goals. Congress came very close to funding resumption of fuel development within the program, and asked for more information on the subject.

The Secretary of Energy announced that the reprocessing plants at Savannah River and at the Idaho National Engineering Laboratory will be shut down in the near future. The RERTR program intends to cooperate to the fullest extent with reactor operators and potential commercial reprocessors to ensure that a viable solution for reprocessing LEU fuel is found.

Consistent with DOE guidance and with a reduced but stable budget projection, the RERTR Program has concentrated its efforts on technology transfer and analytical assistance related to conversion utilizing already developed fuels. The conversion progress achieved to date corresponds to approximately $56 \%$ of what would be needed to convert all the reactors which used to import HEU from the West.

The RERTR Program intends to continue to participate in cooperative efforts to facilitate and accelerate as much as possible the process of eliminating HEU from international commerce. 


\section{REFERENCES}

1. Travelli, A., "Progress of the RERTR Program in 1990," Proceedings of the XIV International Meeting on Reduced Enrichment for Research and Test Reactors, Jakarta, Indonesia, 4-7 November 1991 (to be published).

2. U.S. Nuclear Regulatory Commission: "Safety Evaluation Report Related to the Evaluation of Low-Enriched Uranium Silicide-Aluminum Dispersion Fuel for Use in Non-Power Reactors," U.S. Nuclear Regulatory Commission Report NUREG-1313 (July 1988).

3. Hofman, G. L., Rest, J., and Snelgrove, J. L., "A New Swelling Model and its Application to Aluminum Silicide Research Reactor Fuels," (these proceedings).

4. Woodruff, W. L., Deen, J. R., and Costescu, C. I., "A Comparison of WIMS-D4M Generated Cross-section Data with Monte Carlo," (these proceedings).

5. Bretscher, M. M., Snelgrove, J. L., and Ciocanescu, M., "Analytical Analysis of Startup Measurements Associated with the First Use of LEU Fuel in Romania's 14-MW TRIGA Reactor," (these proceedings).

6. Toma, C., Barbos, D., Ciocanescu, M., Busuioc, P., Whittamore, W., and Snelgrove, J. L., "Measurement and Computations for Neutron Flux in TRIGA HEU Core with Four Experimental LEU Fuel Clusters," (these proceedings).

7. Deen, J. R., Snelgrove J. L., and Papastergiou, C., "Greek Research Reactor Performance Characteristics after Addition of Beryllium Reflector and LEU Fuel," (these proceedings).

8. Matos, J. E., "Analysis for Conversion of the Georgia Tech Research Peactor to LEU Fuel," (these proceedings).

9. Michaels, T., "Status of HEU-LEU Conversions for Non-power Reactors Licensed by the U.S. Nuclear Regulatory Commission," (these proceedings). 


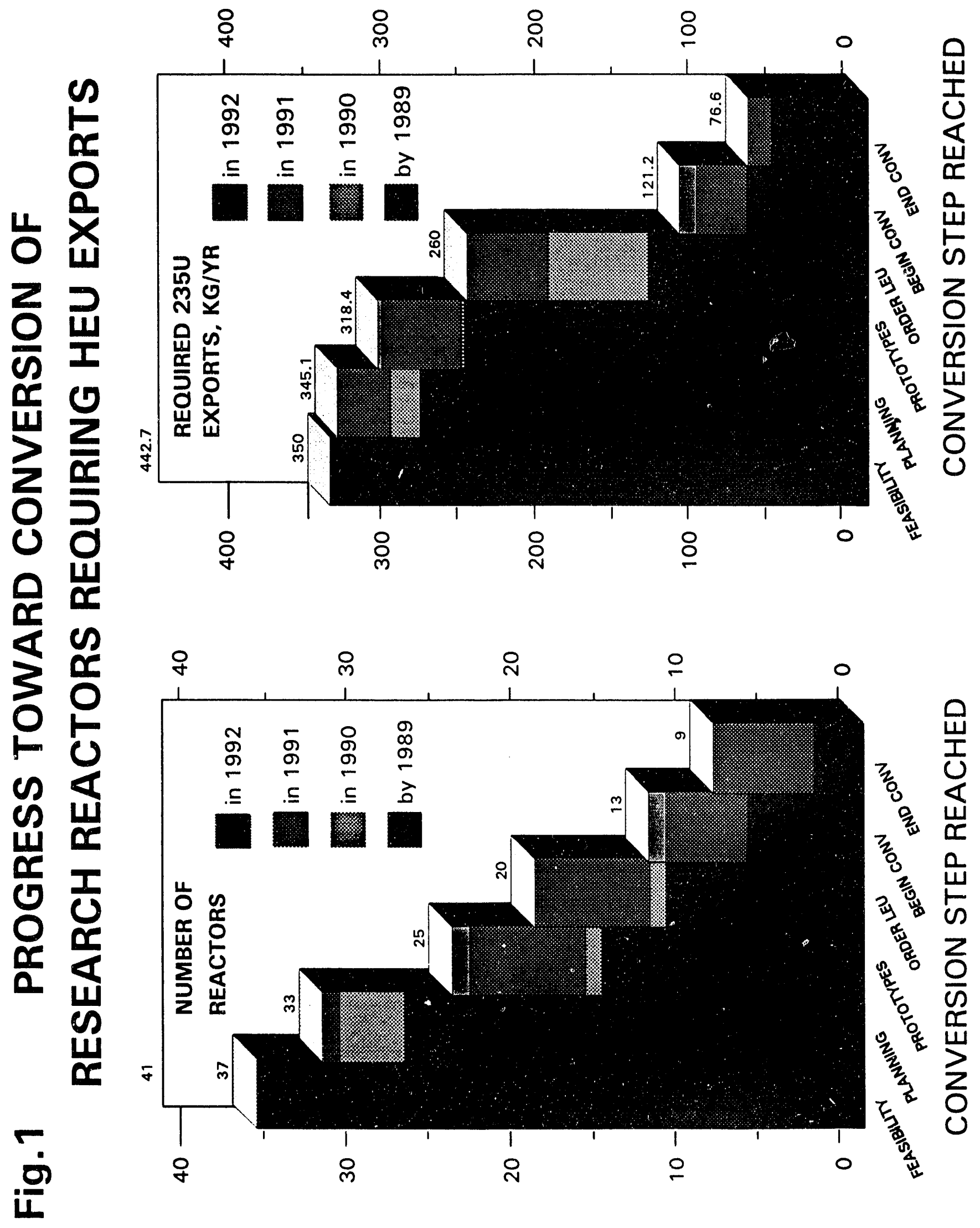



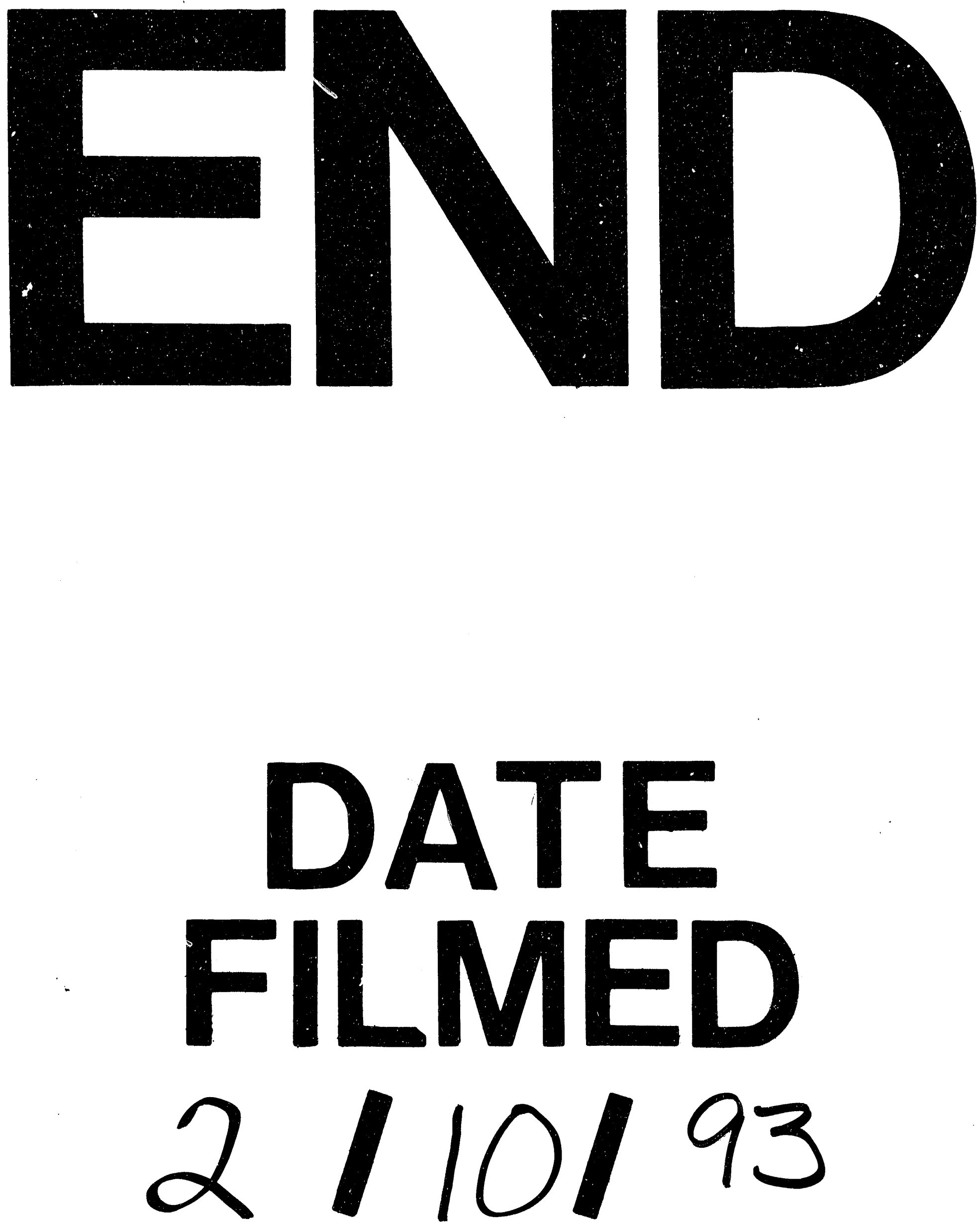